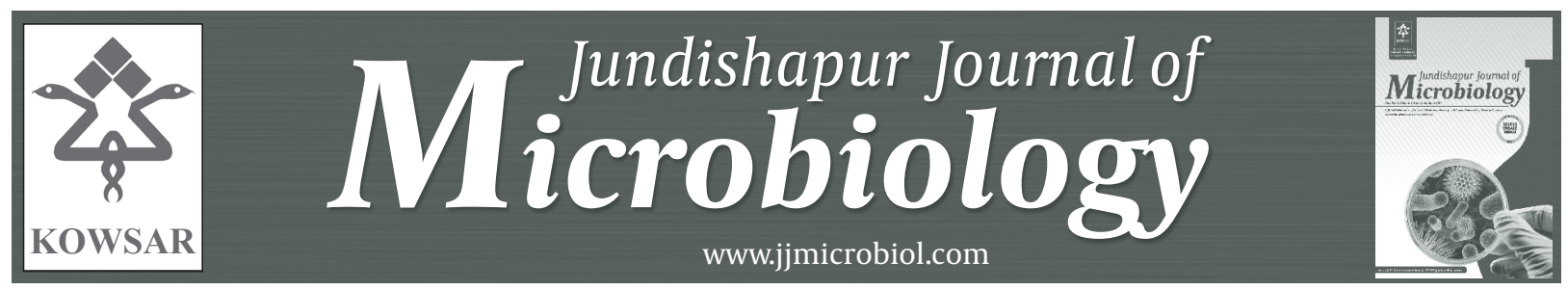

\title{
Serological Survey of Avian Influenza (H9N2)Among Different Occupational Groups in Tehran and Qazvin Provinces in IR Iran
}

\author{
Elaheh Anvar ${ }^{1,2}$, Seyed Masoud Hosseini ${ }^{1,{ }^{*}}$, Masoumeh Tavasoti Kheiri ${ }^{2}$, Vahideh Mazaheri ${ }^{2}$, \\ Kurosh Fazaei ${ }^{3}$, Maryam Shabani ${ }^{3}$, Effat Alizadeh ${ }^{1}$, Mansoureh Tabatabaiean ${ }^{2}$, Ali Torabi ${ }^{2}$ \\ ${ }^{1}$ Department of Microbiology, Faculty of Biological Science, Shahid Beheshti University of Medical Sciences, Tehran, IR Iran \\ ${ }^{2}$ Influenza Research Lab, Pasteur Institute of Iran, Tehran, IR Iran \\ ${ }^{3}$ Department of Poultry Disease, Iran Veterinary organization, Tehran, IR Iran \\ ${ }^{*}$ Corresponding author: Seyed Masoud Hosseini, Department of Microbiology, Faculty of Biological Sciences, Shahid Beheshti University of Medical Sci- \\ ences, Tehran, IR Iran. Tel:+98-21 29902721, Mobil: +98-9123028767, Fax: +98-2122431664, E-mail: seyedmasoudhosseini@ymail.com.
}

\begin{abstract}
A B S T R A C T
Background: In the last decade H9N2 avian influenza viruses had caused outbreaks in poultry in many parts of the world. This subtype could infect other animals such as human and pig. Avian H9N2 virus has acquired receptor binding characteristics typical of human's strains, increasing the potential for reassortment in both human and pig respiratory tracts. This indicates that the A/H9N2 would be a potential threat to human population.

Objectives: The aim of this was to indentify the presence of A/H9N2 virus among different high risk occupational groups, in Tehran and Qazvin provinces in seasonal outbreak in Iran.

Material and Methods: 182 sera were collected from the poultry farms and slaughterhouse workers, and animal vaccinators and also veterinarians in seasonal outbreak (December 2010, January 2011 and July 2011). Hemagglutination Inhibition (HI) and ELISA assays were performed to detect anti-H9 antibody. Sera adsorption was performed to eliminate cross-reactivity between anti-H3 and anti-H9. In HI test the titer $\geq 20$ was considered to be positive.

Results: Only3 (1.64\%) in HI that showed titer $\geq 20$ and 21(11.53\%) sera in ELISA showed OD \&gt; 0.7 were assumed positive for H9 virus infection. Conclusions: The findings of this study show that H9N2 avian influenza virus can infect human. Repeated interspecies transmission H9N2 viruses from poultry to human raises concerns about adapting of this subtype with new host.
\end{abstract}

Keywords: Avian Influenza A; H9N2 Subtype; Occupational Groups; Iran

Copyright () 2013, Ahvaz Jundishapur University of Medical Sciences; Published by Kowsar Corp.

-Article type: Research Article; Received: 08 May 2012; Revised: 18 Aug 2012; Accepted: 30 Sep 2012; Epub: 01 Jun 2013 ; Ppub: Jun 2013 Implication for health policy/practice/research/medical education:

This study aims to indentify the potential existence of H9N2 avian influenza viruses among human population. Repeated interspecies transmission H9N2 viruses from poultry to human raises concerns about adapting of this subtype with new host.

-Please cite this paper as:

Anvar E, Hosseini SM, Tavasoti Kheiri M, Mazaheri V, Fazaei K, Shabani M, et al. Serological Survey of Avian Influenza (H9N2) Among Different Occupational Groups in Tehran and Qazvin Provinces in IR Iran. Jundishapur J Microbiol. 2013; 6 (4): e5441. DOI: 10.5812/ jjm.5441.

Copyright (C) 2013, Ahvaz Jundishapur University of Medical Sciences; Published by Kowsar Corp.

This is an Open Access article distributed under the terms of the Creative Commons Attribution License (http://creativecommons.org/licenses/by/3.0), which permits unrestricted use, distribution, and reproduction in any medium, provided the original work is properly cited. 


\section{Background}

Influenza A viruses belong to the Ortomyxoviridae Family that base on two surface glycoproteins, i.e. the hemagglutinin (HA) and neuraminidase (NA), are classified to different subtypes (1). Among the 16 HA subtype viruses detected in wild birds and poultry throughout the world, Subtypes of H5, H7 and H9 could cross interspecies barriers and infect humans and pigs.

Avian influenza A viruses of subtype H9N2 were first detected in the United States in 1966 (2). This subtype were obtained from domestic pigs in 1998 in Hong Kong .Two strains of A/H9N2 subtypes; Duck/HK/Y280/97(Y280-like) and Quail/HK/G1/97(G1-like) were isolated for the first time from humans in 1999 (3). In 2003, human cases of H9N2 virus were reported in Hong Kong (4). Detection of antibody to H9N2 has been reported from human in southern East Asia during past years, suggesting that additional unrecognized human H9N2 infections have occurred.

Since 1998, H9N2 avian influenza outbreaks have been one of the major problems in the Iranian poultry industry which is now vaccination against this subtype is practiced, routinely (5). Infection of Human reports with avian H9N2 subtype in recent years in Iran indicate that Iranian H9N2 virus may cause some changes in their structure and obtained potential tread to create pandemic in human population (6).

\section{Objectives}

The aim of this study was to monitor the presence of A/ H9N2 antibody among different high risk occupational groups, in Tehran and Qazvin provinces in seasonal outbreak in Iran (December 2010, January 2011, and June 2011) using HI and ELISA assays.

\section{Materials and Methods}

This study was conducted in season outbreakamong different high risk occupational categories including poultry and slaughter workers, veterinarians and vaccinators who are in high risk of INF infection. Samples taken from Tehran and Qazvin provinces that have highest human populations and large numbers of poultry farms and slaughterhouses in Iran. A5 ml Peripheral blood samples from Tehran (No.102) and Qazvin (No. 80) provinces were collected and then transported in ice bag container to the laboratory. 15 blood samples of individuals who have no contact with poultry collected and used as negative controls.

Antibodies to H9N2 avian influenza virus in the serum samples were examined using the hemagglutinationinhibition (HI) and Enzyme-Linked immunosorbent Assay (ELISA). The influenza antigen used for the assays was the locally circulating H9N2 strain. H9N2 anti-serum, A/ HK/1073/99(07/146), that obtained from the National Institute for Biological Standards and Control (NIBSC), used as a positive control. Samples were accompanied with questionnaires on demographic information and data on vaccination history, occupational type exposure, employment history and recent influenza symptoms.

\subsection{Hemagglutination Inhibition (HI) Assay}

This assay was carried out following the WHO influenza laboratory procedures (7). Briefly, sera were treated with receptor destroying enzyme (RDE) and absorbed with the erythrocytes to remove non-specific hemagglutination. A U-bottom 96-well microtiter plates with $0.5 \%$ chicken erythrocytes used. Sera adsorption was performed to eliminate cross-reactivity between anti-H3 and anti-H9 before HI tests. One part of serum was added to two parts of A/panama/2007/99 (H3N2) virus and incubated for one hour at room temperature then storage for two hours at $4^{\circ} \mathrm{C}$. To confirm absence of the virus, serial dilutions were prepared following incubation with RBCs. Negative hemagglutination suggested successful virus removal.

\subsection{Enzyme-Linked Immunosorbent Assay (ELISA)}

Influenza antigen was adjusted to a concentration of 1 $\mu \mathrm{g}$ per $\mathrm{ml}$ in PBS, and $100 \mathrm{ml}$ was added to each well of 96well immunoassay and was incubated overnight at $4^{\circ} \mathrm{C}$. The serum samples were diluted 1/100 in PBS containing $0.5 \%(\mathrm{wt} / \mathrm{v})$ gelatin and $0.05 \%$ Tween 20 . Antigen coated immunoassay plates were washed three times with washing buffer, and $100 \mu \mathrm{l}$ of the diluted serum was added to the wells. Following one hour incubation at $37^{\circ} \mathrm{C}$, the plates were washed 4-5 times with washing buffer. Then, $100 \mu \mathrm{l}$ of horseradish peroxidase-labeled anti-human IgG diluted 1/30,000 in PBS containing 0.5\% (wt/v) gelatin and $0.05 \%$ Tween 20 was added to each well (8).

The plates were incubated for one hour at $37^{\circ} \mathrm{C}$ and washed 4-5 times with wash buffer. One hundred microliters of TMB substrate (3,3`, 5, $5^{-}$-tetra methylbanzidine) was added to each well and stopped with an equal volume of $2 \mathrm{~N}$ sulfuric acid after color development. The absorbance was measured at $450 \mathrm{~nm}$ with spectrophotometer. Negative control human sera were tested in each ELISA to establish threshold. An OD of $>0.7$ was considered positive for the ELISA. Data were analyzed with SPSS 17, Chi-Square test.

\section{Results}

In HI test, only three (1.64\%) samples from two provinces were antibody positive to A/H9N2. One sample was from Tehran and two samples were from Qazvin province. In ELISA, 21 (11.53\%) sera were positive that 9 and 12 sera were 
from Tehran and Qazvin provinces, respectively (Table 1). Based on the questionnaire, age, gender and poultry contact history were all not statistically associated with H9 virus infection in two serologic assays but high significant association between ELISA and HI assay with $P<0.01$ was found.

\begin{tabular}{|c|c|c|c|c|c|c|c|c|}
\hline \multirow[t]{2}{*}{ Viral subtype } & \multirow[t]{2}{*}{ Province } & \multirow[t]{2}{*}{ Groups } & \multirow{2}{*}{$\begin{array}{l}\text { S a m p l e } \\
\text { Numbers }\end{array}$} & \multicolumn{3}{|c|}{ HI titer (\%) } & \multicolumn{2}{|l|}{ ELISA } \\
\hline & & & & $\operatorname{Neg}(<10)$ & $\operatorname{Neg}(=10)$ & $\operatorname{Pos}(\geq 20)$ & Neg & Pos \\
\hline & & SW $^{\mathrm{a}}$ & 51 & 100 & 0 & 0 & $48(94.11 \%)$ & $3(5.82)$ \\
\hline & Tehran & $\mathbf{P W}^{\mathrm{a}}$ & 36 & $33(91.66 \%)$ & $2(5.6)$ & $1(2.7)$ & $30(83.33)$ & $6(22.22)$ \\
\hline \multirow[t]{4}{*}{ H9N2 } & & $\mathbf{v}^{\mathrm{a}}$ & 15 & 100 & 0 & 0 & 0 & 0 \\
\hline & & swa & 46 & $43(94)$ & $1(2)$ & $2(4)$ & $34(73.91)$ & $12(26.08)$ \\
\hline & Qazvin & $\mathbf{P W}^{\mathrm{a}}$ & 24 & 100 & 0 & 0 & 100 & 0 \\
\hline & & $\mathbf{v}^{\mathrm{a}}$ & 10 & 100 & 0 & 0 & 100 & 0 \\
\hline
\end{tabular}

a Abbreviations: SW, Slaughter-house Workers; PW, Poultry Workers; V, Vaccinators and Veterinarians.

\section{Discussion}

Our study indicated that H9N2 avian influenza viruses could cause infection in humans by long time direct contact with poultry. Subtype of H9N2 is classified as low-pathogenicity viruses both by molecular characterization and by patho-typing. Viruses of this subtype are unique among low pathogenicity avian influenza viruses in that they infect a wide variety of species, including chickens, quail, turkeys, ducks, geese, pigs, and humans. After the first outbreak of H9N2 avian influenza in Iran in early 1998 that has imposed great economical losses to the poultry industry, some general and molecular-based studies have been conducted mostly on hemagglutinin (HA) protein to evaluate its probable significant mutations related to varied pathogenicity features of the local avian influenza isolates.

Serological surveys using HI assay, showed positive rate of H9N2 antibody presence in human population, such as in Hong Kong workers (30\%) in chine, in Shenzhen province (26\%), Guangdong province (9.52\%) and poultry farm workers of Guangdong province $(5.1 \%)(9,10)$. Human infections with the H9N2 subtype have been reported in Iran. A previous seroepidemiological study on H9N2 infection was carried out in Tehran province in 2006 with a positive rate of $37.7 \%$ (9). Another studies identified possible H9 infections in humans in other reigns in Iran (10, 11).

The lower titers in this study might result from mild natural this subtype that not creates marked antibody responses. Furthermore, these results could reflect the decay of antibody titers over time. Difference between ELISA and HI results reflect to isotype of antibody to be detected by these tests. The ELISA used in this study was designed to detect IgG specific for H9N2 virus while HI assay can detect IgM antibodies produced to the virus (12). In early viral infection, primary antibody that appears is IgM. Therefore, HI test may be useful in detecting animals exposed recently to Influenza virus. In conclusion, we have demonstrated H9 sero-positivity in adjacent and most populated provinces in Iran. Although no documented clinical cases of H9 infection in human during this study were reported, repeated interspecies transmission $\mathrm{A} / \mathrm{H} 9 \mathrm{~N} 2$ viruses from poultry to human raises concerns about adapting of this subtype with new host.

\section{Acknowledgements}

Authors would like to thank the Iranian Veterinary Organization for helping us to provide samples.

\section{Financial Disclosure}

None declared.

\section{Funding/Support}

None declared.

\section{Authors' Contribution}

All authors contributed equally.

\section{References}

1. Jia NA, de Vlas SJ, Liu YX, Zhang JS, Zhan L, Dang RL, et al. Serological reports of human infections of $\mathrm{H} 7$ and $\mathrm{H} 9$ avian influenza viruses in northern China.J Clin Virol. 2009;44(3):225-229.

2. FeiFei G, JinPing Z, Jian L, Jian W, WeiYi Z, LiPing S, et al. Genetic evolution of $\mathrm{H} 9$ subtype influenza viruses from live poultry markets in Shanghai, China.J Clin Microbiol. 2009;47(10):3294-300.

3. Uyeki TM, Chong YH, Katz JM, Lim W, Ho YY, Wang SS, et al. Lack of evidence for human-to-human transmission of avian influenza A (H9N2) viruses in Hong Kong, China 1999. Emerg Infect dis. 2002;8(2):154.

4. Butt KM, Smith GJD, Chen H, Zhang LJ, Leung YHC, Xu KM, et al. Human infection with an avian H9N2 influenza A virus in Hong Kong in 2003. JClin Microbiol. 2005;43(11):5760-5767.

5. Marandi MV, Fard MHB. Isolation of H9N2 subtype of avian influenza viruses during an outbreak in chickens in Iran. Iran Biomed J. 2002;6(1):13-17. 
6. Homayounimehr AR, Dadras H, Shoushtari A, Pourbakhsh SA. Sequence and phylogenetic analysis of the haemagglutinin genes of H9N2 avian influenza viruses isolated from commercial chickens in Iran. Trop Anim health Prod. 2010;42(6):1291-1297.

7. World Health organization (WHO). Manual on Animal Influenza Diagnosis and surveillance 2002.

8. Rowe T, Abernathy RA, Hu-Primmer J, Thompson WW, Lu X, Lim $\mathrm{W}$, et al. Detection of antibody to avian influenza A (H5N1) virus in human serum by using a combination of serologic assays. $J$ Clin Microbiol.1999;37(4):937-943.

9. Alizadeh E, Kheiri MT, Bashar R, Tabatabaeian M, Hosseini SM. Avian Influenza (H9N2) among poultry workers in Iran. Iran J
Microbiol. 2009;1(3):3-6.

10. Hadipour MM. Seroprevalence of H9N2 Avian Influenza Virus in Human Population in Boushehr Province, Iran. Asian J Anim Vet Adv. 2011;6(2):196-200.

11. Hadipour MM. H9N2 avian influenza virus antibody titers in human population in fars province, Iran. Rev BRAS Ciência Avícola. 2010;12(3):160-4.

12. Yoon KJ, Janke BH, Swalla RW, Erickson G. Comparison of a commercial H1N1 enzyme-linked immunosorbent assay and hemagglutination inhibition test in detecting serum antibody against swine influenza viruses. J Vet Diagn Invest. 2004;16(3):197. 